\title{
EFETIVITAS METODE INQUIRY LEARNING DALAM MENINGKATKAN KEMAMPUAN ANALISIS PADA MATERI IPA SISWA KELAS III SDN TLOGOANGUNG
}

\author{
Kiky Chandra Silvia Anggraini \\ Universitas Islam Lamongan \\ e-mail: qcandra.sa @unisla.ac.id
}

\begin{abstract}
This study aims to examine the use of inquiry methods for the ability of student analysis. Based on the M Problem that is faced by the teachers of the school base on learning of science. The method is carried out by conducting preexperiment by conducting a pretest and posttest during the research. The instrument used in the form of a written test and for data analysis using paired sample t test with the help of SPSS 25. After paired test $t$ sample test is known if the significance value is 0.00 or smaller than 0.005. which means Ha was accepted and Ho rejected.
\end{abstract}

Keywords: inquiry, analytical skills, social studies

\section{A. Pendahuluan}

Pendidikan merupakan usaha sadar dan terencana untuk membantu perkembangan dan kemampuan anak agar bermanfaat bagi kepentingan hidupnya sebagai individu dan sebagai warga Negara. Pendidikan adalah usaha manusia untuk membina kepribadian sesuai dengan nilai-nilai di dalam masyarakat, kebudayaan dan agama (Umar Tirtarahardja dan La Sulo, 2005). Pendidikan adalah aktivitas dan usaha manusia dalam meningkatkan kepribadiannya dengan jalan membina potensi rohaninya (pikir,rasa, karsa, cipta, dan budi nurani) dan jasmani (pancaindera dan keterampilan).

Keberhasilan pembelajaran dipengaruhi oleh beberapa faktor diantaranya faktor guru, faktor siswa, kurikulum dan lingkungan. Guru sebagai komponen yang sangat menentukan dalam kegiatan pembelajaran. Guru berperan sebagai penyalur ilmu, motivator pembimbing dan lain-lain. Sebagai fasilitator guru harus menciptakan lingkungan belajar yang menyenangkan dan membimbing siswa untuk aktif dalam proses pembelajaran, sehingga proses pembelajaran dapat berjalan dengan baik dan menghasilkan perubahan pada diri peserta didik dalam pengetahuan, sikap dan keterampilan.

Penggunaian metode cermah yang masih mendomiansi pembelajaran IPS membuat siswa lebih bersifat pasir karena selama pembelajaran siswa akan memdapatan informasi yang didapat melalui penjelasan guru saja. Padahal dalam pembelajaran IPA perlu adanya praktek dan turut aktif dalam pembelajaran. Keadaan yang terus 
menurus menggunakan motode ceramh akan membuat siswa tidak mempunyai kemampuan analisi yang baik. Pada tingkatan sekolah dasar pelu adanya dibiasakan untuk pembelajaran yang bersifat kognitif tinggakt tinggi misalnya dengan kemampuan analisis. hal ini sesuai dengan pendapat Atmad dan Setyaningsih (A.Atmadi dan Y. Setianingsih., 2000) mengatakan bahwa siswa harus dilatih untuk secara aktif bertanya, mengamati, menyelidiki atau menemukan jawaban atas pertanyaan yang diajukan oleh guru atau teman sebaya sejak awal pendidikan dasar

Menganalisis adalah kemampuan untuk menguraikan suatu materi menjadi bagianbagiannya. Kemampuan untuk menganalisis dapat: (a) analisis elemen (mengidentifikasi bagian-bagian materi); (B) analisis hubungan (untuk mengidentifikasi hubungan); (C) mengorganisasi analisis prinsip (mengidentifikasi organisasi / organisasi). Melalui keterampilan analitis, peserta didik dapat memisahkan dan membangun pemahaman berdasarkan komponen-komponennya untuk melihat hubungan bagian-bagian dan kesesuaiannya.

Kemampuan analisis dalam pembelajaran bisa ditumbuhkan melalui tiga tahapan yaitu dengan memberikan pemahaman konsep, memberian teorima dan permasalah (Bezusova, Richter, Sugrobova, Chugainova, \& Shestakova, 2017) memberikan konsep artinya menganalisis subjek, faktor menyebab. pemberian terorema berguna untuk mengetahui hubungan antar variabel penyusun dan hubunagn variabel penyusun dengan masalah. pemberian masalah digunakan untuk identifikasi maalah, memberikan solusi untuk mengatasi permasalahan.

Berdasarkan hasil observasi di SDN Tlogoagung menemukan kemampuan analisis masih rendah, hal tersebut dibuktikan dengan hasil evaluasi ulangan harian 60\% dari 12 siswa yang hasil belajarnya dibawah KKM, dan $40 \%$ siswa yang hasil belajarnya diatas KKM (Kriteria Ketuntasan Minimal) yang telah ditentukan yaitu 75. Hasil belajar yang rendah tersebut disebabkan karena adanya beberapa permasalahan.

Ada beberapa permasalahan yang terjadi pada hasil belajar siswa SDN Tlogoagung mata pelajaran IPA materi energi dan perubahannya yaitu (1) proses pembelajarannya hanya diarahkan pada kemampuan siswa untuk menghafal informasi, otak siswa dipaksa hanya untuk mengingat dan menimbun berbagai informasi, (2) guru tidak menggunakan media saat pembelajaran, (3) guru belum sepenuhnya melaksanakan pembelajaran secara aktif dan kreatif, (4) guru belum menggunakan metode yang tepat berdasarkan karakter materi pelajaran, (5) guru hanya terpaku pada buku teks sebagai satu-satunya sumber belajar mengajar serta, (6) guru masih menggunakan metode konseptual yang isinya guru menjelaskan pada siswa lalu siswa menulis atau mencatat penjelasan dari guru.

Beberapa masalah tersebut menyebabkan keterampilan proses pembelajaran kurang optimal. Contohnya saja pada saat pembelajaran IPA pada materi energi dan 
perubahannya siswa kelas III cenderung pasif karena seharusnya di materi tersebut siswa bisa diajak untuk praktek langsung atau mencari masalah-masalah yang ada di kehidupan sehari-hari yang berhubungan dengan materi energi dan perubahannya.

Hakikat pembelajaran IPA di SD menekankan pada pemberian pengalaman belajar secara langsung melalui penggunaan dan pengembangan keterampilan proses dan sikap ilmiah. Pengajaran dikatakan baik jika proses yang terjadi memberikan hasil yang baik yaitu tercapainya tujuan pembelajaran. Salah satu cara agar tujuan pembelajaran dapat tercapai adalah dengan menggunakan metode pembelajaran yang sesuai dengan karakteristik siswanya (Susanto, 2013).

Metode inquiry merupakan proses bervariasi dan meliputi kegiatan-kegiatan mengobservasi, merumuskan pertanyaan yang relevan, mengevaluasi buku dan sumbersumber informasi lain secara kritis, merencanakan penyelidikan atau investigasi, mereview apa yang telah diketahui, melaksanakan percobaan atau eksperimen dengan menggunakan alat untuk memperoleh data, menganalisis dan mengitrepetasi data, serta membuat prediksi dan mengomunikasikan hasilnya.

Model pembelajaran inkuiri terbimbing menciptakan suasana belajar yang menyenangkan dan membuat siswa lebih aktif (R. B. Sund \& L. W Trowbridge, 1967) Siswa dituntut untuk menentukan konsep dan teori mereka melalui bimbingan yang diberikan oleh guru. Sebagai fasilitator, guru akan membantu siswa merencanakan dan melaksanakan penyelidikan (Neuby, 2010)

Sintaks model pembelajaran inkuiri terbimbing oleh Joyce and Weil (Joyce, Bruce., 2000) yang meliputi identifikasi dan penentuan ruang lingkup masalah, perumusan hipotesis, merancang eksperimen, menafsirkan data, dan membuat kesimpulan. dimana langkah-langkah tersebut misalnya Membangun hipotesis, pengujian, evaluasi, dan penerapan informasi baru adalah bagian tak terpisahkan dari penyelidikan yang merupakan keterampilan berpikir tingkat tinggi (Neuby, 2010) Berdasarkan uraian di atas, dapat dilihat bahwa model pembelajaran inkuiri menuntut siswa untuk memiliki keterampilan berpikir tingkat tinggi atau high order thinking skilss (HOTS).

Di tingkat sekolah dasar masih banyak guru yang menekankan proses menghafal daripada meminta siswa mereka untuk melalui proses penemuan mereka (Margunayasa, Dantes, Marhaeni, \& Suastra, 2019). Model pembelajaran atau ekspositori yang dianggap sebagai salah satu penyebab ketidakmampuan dalam kemampuan analisis dalam informasi yang sulit didapatkan.

Siswa dituntut memiliki keterampilan berpikir tingkat tinggi untuk menyelesaikan masalah yang terkait dengan masalah lokal dan global melalui kegiatan pembelajaran, salah satunya adalah kemampuan berpikir analitis (Osman, Hiong, \& Vebrianto, 2013). Model pembelajaran harus mampu membuat siswa melakukan investigasi terhadap masalah yangada sekeliling siswa yang didapat melalui penyelidikan sendiri dan 
mampu menyelesaikan masalah di masa depan (Secker, 2002 ) (Boyd, S., \& Hipkins, 2012) Diharapkan dengan melibatkan fenomena sosial di sekitar siswa, sehingga siswa akan aktif melakukan observasi, eksperimen dan penyelesaian masalah sehingga siswa tidak hanya mampu memperoleh hasil belajar dari pengetahuan dan pemahaman saja.

Model pembelajaran inkuiri terbimbing membuat siswa lebih aktif, mendorong pemikiran kritis, dan menciptakan suasana yang menyenangkan (Suntusia, Dafik, \& Hobri, 2019) Dalam Inkuiri terbimbing, proses dapat dilakukan dengan melibatkan proses mengidentifikasi pertanyaan, mengumpulkan dan mensintesis informasi, dan mengembangkan pemahaman reflektif (Duran \& Dökme, 2016)

Berdasarkan latar belakang tersebut penelitian yang berjudul efetivitas metode inquiry learning dalam meningkatkan kemampuan analisis pada materi ipa siswa kelas III SDN Tlogoangung.

Berdasarkan kerangka hipotesis diajukan setelah merumuskan masalah, hal ini cukup berasalan karena hipotesis yang dibangun berdasarkan jawaban sementara peneliti Hipotesis dalam penelitian ini sebagai berikut.

Ho : Penerapan model pembelajaran inkuiri tidak efektif dalam meningkatkan kemampuan analisis IPA PADA Siswa Kelas IV III SDN Tlogoangung.

Ha Penerapan model pembelajaran inkuiri efektif dalam meningkatkan kemampuan analisis IPA PADA Siswa Kelas IV SD SDN Tlogoangung.

\section{B. Metode}

Penelitian ini merupakan penelitian eksperimen semu yang menggunakan penelitian pretest dan postest control desain. Pretest dilakukan untuk mengetahui keadaan awal subjek penelitian sebelum diberikan perlakuan, sehingga peniliti akan mengetahui kondisi awal subjek penelitian dan kondisi setelah diberikan perlakuan yang hasilnya dapat dibandingkan atau dilihat perubahannya.Posttest dilakukan untuk mengetahui keadaan subjek penelitian setelah diperlakukannya perlakuan.

Intrumen Tes tulis IPS Sebelumnya telah dilakukan uji validasi muka dan validadi butir soal. berdasarkan hasil validasi muka di dapatkan skor sebesar 93,5 yang berati soal valid untuk dilakukan penelitian. Sedangkan dari hasil validasi butir. yang dilakukan di luar sample uji coba kemudian dianalisis denggan nilai Corrected ItemTotal Correlation berbantuan spss 16. Diketahui dari 20 soal uraian terdapat 20 soal yang tergolong valid. Setelah ditemukan validitasnya, maka perlu dilakukan pengukuran reabilitas, dapat ketahui jika nilai Alpha Cronbach.s yang dihasilkan sebesar 0.878 . Berdasarkan koefisiensi reabilitas yang diatas 0,80 , maka dapat dikatakan jika tes tulis IPA mempunyai tingkat reabilitas yang tinggi. Teknik analisis data menggunakan uji paired sampel T-Tes yang sebelumnya akan dilakukan uji prasyarat yaitu uji normalitas. 


\section{Hasil dan Pembahasan}

Siswa yang akan menjadi kelompok penelitian akan diberikan perlakuakn berubah metode inkuiri terbimbing untuk meningktkan kemampuan analisis siswa. selama pembelajaran berlangsung sebanyak empat kali pertemuan dimana hari pertma siswa masih belum terbiasa mendapatkan inkuri terbimbing. namun dihari- hari berikutnya siswa semakin bersemangat mendapatkan inkuiri terbimbing.

Adapapun skema pengembangn metode inkuir terbimbing guna meningkatkan kemampuan analisis yang dilakukan selama proses pembelajaran sebagai berikut:

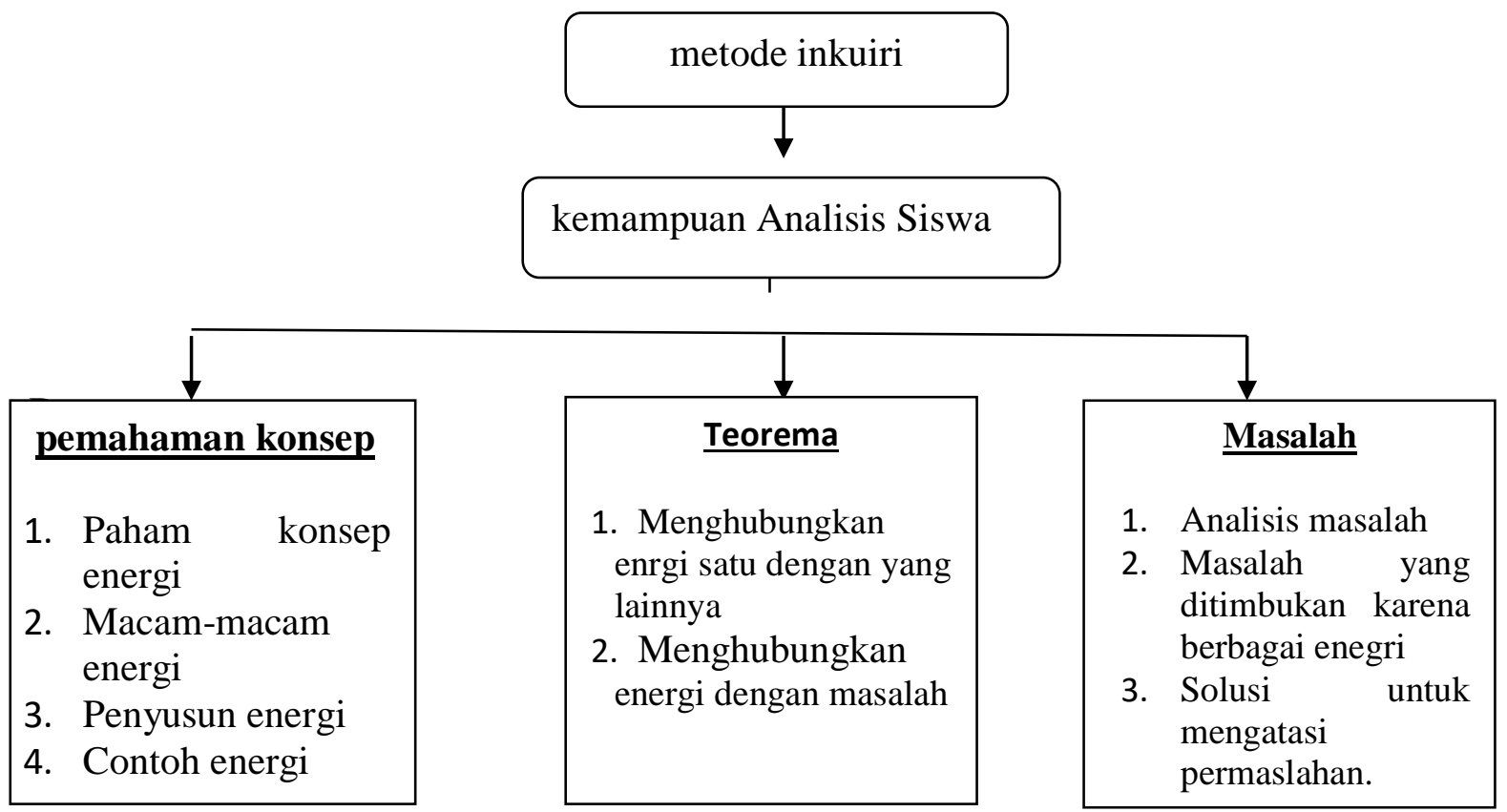

Gambar 2. Prosedur penelitian metode inkuiri terhadap kemampuan analsis

Siswa selama metode inkuiri dilakukan melakukan pengembangan kemampuan analisis adalah dengan cara siswa diberikan pemahaman konsep, teorema dan masalah. siswa akan terbiasa mengetauhi konsep inti terlebih dalu baru bisa melangkah ke tahapan yang lebih tinggi, setelah mengetahui konsep siswa akn dibaisakan untuk melakukan memecahan konsep menjadi bagian bagian kecil serta penganalisan permasalahan.

Berdasarkan penelitian yang dilakukan oleh para peneliti, model pembelajaran penyelidikan dipandu lebih baik dari model pembelajaran ekspositori dalam beberapa aspek: 1) siswa bertugas mencari informasi atau pengetahuan mereka sehingga siswa lebih aktif daripada harus menunggu guru untuk memberikan pengetahuan; 2) posisi guru bukanlah pusat pembelajaran melainkan sebagai fasilitator selama proses 
pembelajaran. Guru memberikan instruksi yang memudahkan siswa untuk mengeksplorasi informasi yang tepat. Belajar adalah pusat siswa di mana siswa menjadi partai dominan untuk mendapatkan berbagai jawaban atas pernyataan yang telah diberikan; 3) Melatih siswa untuk berpikir sistematis, logis dan kritis atau mengembangkan kemampuan intelektual sebagai bagian dari proses mental dan 4) Siswa diminta untuk menentukan konsep dan teori-teori mereka sendiri melalui petunjuk yang diberikan oleh guru. Petunjuk yang diberikan dalam menentukan konsep dan teori-teori mereka sendiri melalui petunjuk yang diberikan oleh guru. Petunjuk yang diberikan adalah dalam bentuk membimbing pertanyaan. Guru juga memberikan penjelasan yang diperlukan ketika siswa melakukan percobaan atau memilih informasi yang akan dipilihKelompok yang mendapatkan perlakuan dengan menggunakan model inkuiri Kelas ini mendapatkan pengujian sebanyak 2 kali yaitu pretest dan posttest. Pretest dilakukan sebelum siswa mendapatkan model pembelajaran inkuiri murni, sedangkan posttest adalah pengujian yang dilakukan setelah model pembelajaran inkuri terbimbing dilakukan.

Adapun hasil dari nilai pretest ,hal ini nampak pada Tabel 1 sebagai berikut

\section{Descriptive Statistics}

\begin{tabular}{lr|r|r|r|r} 
& N & Minimum & Maximum & Mean & Std. Deviation \\
\hline posstest & 30 & 77 & 97 & 87,67 & 6,397 \\
\hline pretest & 30 & 42 & 67 & 56,50 & 7,114 \\
\hline Valid N (listwise) & 30 & & & & \\
\hline
\end{tabular}

Berdasarkan data tersebut diketehui jika pada tes pretest siswa mendapatkan nilai minum sebesar 42 dan nilai maksimal sebesar 67. Pada kegaiatn posttest diketahui jika siswa mendapatka nilai minimuns ebsar 77 dan nilai maksminal sebesar 97. berdasarkan data ini diketuhi jikanilai posttest mendapatkan nilai yang lebih baik dari nilai pretest atau setelah diberikan perlakukan nilai siswa cenderung mengalami kenanikan dibandingkan dengan saat belum menggunakan metode inkuri. hal ini nampak pada grafik 1 di bawah ini:

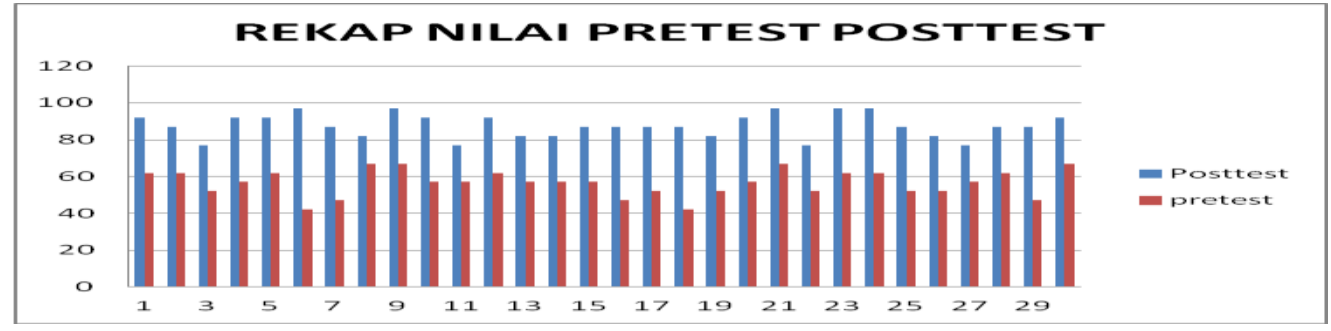

Grafik 1

Grafik uji pretest dan posstes hasil belajar siswa 
Sebelum peneliti melakukan uji hipotesis maka dilakukan uji yang akan mengukur prasayart dari uji SPSS Paired Sampel t-tes dengan melakukan uji normaloitas yang bertujuan untuk menguji kenormalan data dalam penelitian ini. Pengujia uji nornmalitas tampak pada tabel 2 dibawah ini

\section{Tabel 2 Uji normalitas}

\begin{tabular}{|c|c|c|}
\hline \multicolumn{3}{|c|}{ One-Sample Kolmogorov-Smimov Test } \\
\hline & & $\begin{array}{l}\text { Unstandardiz } \\
\text { ed Residual }\end{array}$ \\
\hline$N$ & & 30 \\
\hline \multirow{2}{*}{ Normal Parameters ${ }^{a \cdot b}$} & Mean & .0000000 \\
\hline & Std. Deviation & 6,80413488 \\
\hline \multirow[t]{3}{*}{ Most Extreme Differences } & Absolute & .139 \\
\hline & Positive & .080 \\
\hline & Negative & -.139 \\
\hline Test Statistic & & .139 \\
\hline Asymp. Sig. (2-tailed) & & $.142^{\circ}$ \\
\hline
\end{tabular}

Berdasarkan Uji Normaltas diatas dikethui jika nilai uji normalitas data pretest dan Posttest sebesar 0.142 atau lebih besar dari 0.05 dapat disimpulkan jika pretest dan posttes berasal dari data yang berdistribusi normal.

Setelah dilakukan uji normalitas senagai uji pryarata akan dilakukan uji paired sampel t tes dnegan berbantuan SPSS versi 25.00. berikut ini tabel 3 adalah hasil dari uji Paired Sampel T tes.

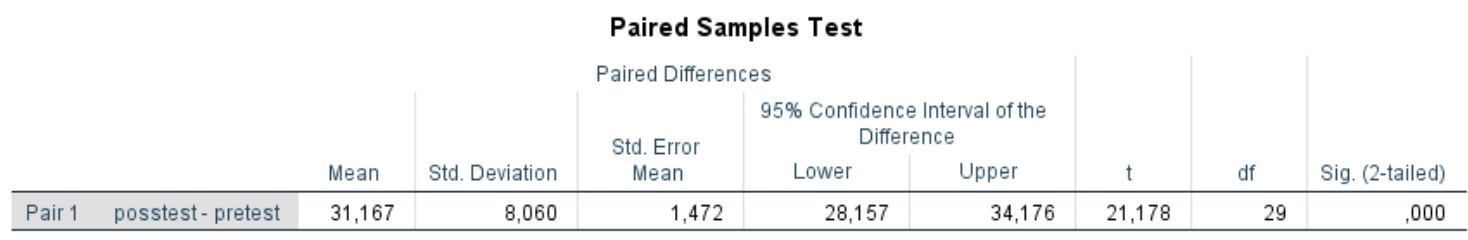

Berdasarkan perhitungan dengan rumus uji t independent sampel test menggunakan SPSS versi 25. Pada bagian Equal variances assumed nilai sig.(2 tailed) sebesar 0,000 < 0,05, maka dapat dikatakan Ho ditolak sehingga Ha (Metode inquiry learning efektif terhadap kemampuan anlisis pada pembelajaran IPA pada materi energi dan perubahannya siswa kelas III SDN Tlogoagung) diterima. Dengan demikian dapat disimpulkan terdapat perbedaan yang signifikan antara rata-rata hasil belajar siswa kelas eksperimen dan kelas kontrol.

\section{Simpulan}

Metode inkuiri mampu meningkatkan kemampuan analisis pada pelajaran IPA mengalmi peningkatan hasil belajar pada siswa SDN Tlogoagung. Hal ini berdasarkan uji paired sampel test yang dilakukan. Selama pembelajaran siswa lebih beraktif dalam 
setiap pembelajaran karena siswa saling tukar pendapat pengerahuan dan mencari berbagai informasi dari berbagai sumber, sehingga pembelajaran bersifat lebih menyenangkan karena guru bukan hanya ceramah.

\section{Daftar Rujukan}

A.Atmadi dan Y. Setianingsih. (2000). Transformasi Pendidikan. Yogyakarta: Penerbit Universitas Sanata Dharma.

Bezusova, T. A., Richter, T. V., Sugrobova, N. Y., Chugainova, L. V., \& Shestakova, L. G. (2017). Types of work in forming analytic and synthetic activity skills in teaching the algebra course. Eurasia Journal of Mathematics, Science and Technology Education, 13(11), 7257-7267. https://doi.org/10.12973/ejmste/79443

Boyd, S., \& Hipkins, R. (2012). Student inquiry and curriculum integration: shared origins and points of difference (Part A). Research Information for Teachers, $13(1), 15-23$.

Duran, M., \& Dökme, I. (2016). The effect of the inquiry-based learning approach on student's critical-thinking skills. Eurasia Journal of Mathematics, Science and Technology Education, 12(12), 2887-2908. https://doi.org/10.12973/eurasia.2016.02311a

Joyce, Bruce., \& W. (2000). Models of Teaching. Amerika: A. Pearson Education Company.

Margunayasa, I. G., Dantes, N., Marhaeni, A. A. I. N., \& Suastra, I. W. (2019). The effect of guided inquiry learning and cognitive style on science learning achievement. International Journal of Instruction, 12(1), 737-750. https://doi.org/10.29333/iji.2019.12147a

Neuby, B. (2010). Inquiry Teaching in the College Classroom. The Journal of Effective Teaching, 10(1), 4-21.

Osman, K., Hiong, L. C., \& Vebrianto, R. (2013). 21st Century Biology: An Interdisciplinary Approach of Biology, Technology, Engineering and Mathematics Education. Procedia - Social and Behavioral Sciences, 102(Ifee 2012), 188-194. https://doi.org/10.1016/j.sbspro.2013.10.732

Robert B Sund; Leslie W Trowbridge. (1967). Teaching science by inquiry in the secondary school. Columbus, Ohio: C.E. Merrill Books.

Secker, C. Von. (2002). The Journal of Educational Research Effects of Inquiry-Based Teacher Practices on Science Excellence and Equity Effects of Inquiry-Based Teacher Practices on Science Excellence and Equity. The Journal of Educational Research, 953, 151-160. https://doi.org/10.1080/00220670209596585

Suntusia, Dafik, \& Hobri. (2019). The effectiveness of Research Based Learning in improving students' achievement in solving two-dimensional arithmetic sequence problems. International Journal of Instruction, 12(1). https://doi.org/10.29333/iji.2019.1212a

Susanto, A. (2013). Teori Belajar Pembelajaran di Sekolah Dasar. Jakarta: Prenada Media Group.

Umar Tirtarahardja dan La Sulo. (2005). Pengantar Pendidikan. Jakarta: Rineka Cipta. 